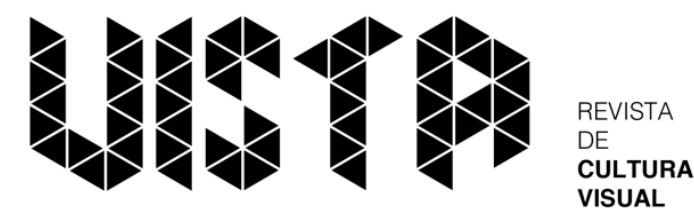

\section{O “paraíso tropical distópico” em Rio 50 Degrees - Carry on Carioca}

\author{
Ana Teresa Gotardo
}

\section{Resumo:}

Este artigo visa compreender os imaginários sobre o Rio de Janeiro em seu "momento olímpico" por meio de uma análise crítica dos primeiros $14 \mathrm{~min}$ do documentário Rio 50 Degrees - Carry on Carioca, dirigido por Julien Temple para o programa Imagine, da rede britânica BBC. Com a primeira data de exibição em maio de 2014 e última em setembro de 2016, o documentário televisivo, que possui 1h45min de duração, utiliza especialmente imagens de arquivo e música brasileira como fios condutores da narrativa para construir sentidos sobre um "paraíso tropical distópico" de "altos emocionantes e baixos aterrorizantes". Desta forma, problematiza o ideal almejado pela marca "cidade oficial" por meio da exploração das ideias de "cidade partida", da violência e do abismo social presentes no cotidiano dos cidadãos. Além disso, atribui outros sentidos às imagens de arquivo, documentais ou ficcionais, em um movimento de reconfiguração do presente por meio do questionamento e de reconstrução de memórias que permanecem sólidas nos imaginários até os dias presentes.

Palavras-chave: Marca Rio; imaginários; distopia; documentário; televisão.

\section{Abstract:}

This article aims to understand the imaginary about Rio de Janeiro in its "Olympic moment" through a critical analysis of the first $14 \mathrm{~min}$ of the documentary Rio 50 Degrees - Carry on Carioca, directed by Julien Temple and broadcasted by the BBC's program Imagine. With its first airing date in May 2014 and last in September 2016, the 1h45min television documentary especially uses archival images and Brazilian music as guiding for the narrative to construct meaning about a "dystopian tropical paradise" of "exciting highs and terrifying lows". Thus, it problematizes the 
ideal targeted by the "official" city branding plan by exploring the ideas of "divided city", the violence and the social abyss present in the daily lives of citizens and also attributes other meanings to archival images (documentary or fictional), in a movement of reconfiguration of the present through the questioning and reconstruction of memories that remain solid in the imaginary until the present day.

Keywords: brand Rio; imaginary; dystopia; documentary; television.

\section{Introdução}

Desde que foi eleita uma das cidades-sede da Copa do Mundo de Futebol de 2014 e sede dos Jogos Olímpicos de Verão de 2016, a cidade do Rio de Janeiro passou por diversas alterações em seu tecido urbano para que fosse possível acolher os maiores mega eventos esportivos mundiais. Uma das questões centrais que norteava as transformações da metrópole dizia respeito à necessidade de (re)construção da imagem da cidade, especialmente em relação à violência (e à necessidade de se construir uma sensação de segurança para atrair turistas e investidores), mas também ao objetivo de se construir uma cidade global ${ }^{1}$, tal como pode ser visto tanto em documentos oficiais, como o Dossiê de Candidatura do Rio de Janeiro a sede dos Jogos Olímpicos e Paraolímpicos de 2016 (Comitê de Candidatura Rio 2016, 2009) e o Plano Aquarela 2020 (Instituto Brasileiro de Turismo, 2009), quanto em narrativas documentais sobre a cidade olímpica.

A construção da "cidade olímpica" é uma trama complexa, composta por diversos nós que perpassam inúmeras áreas de conhecimento, tais como Arquitetura e Urbanismo, Geografia, Estudos do Esporte, Sociologia, dentre outros. No que diz respeito ao campo da Comunicação e das Relações Públicas, é necessário compreender a cidade como organização a ser vendida e consumida e, portanto, como atuam os processos de (re)construção de sua imagem, tanto em relação aos discursos que são emitidos pelos agentes "oficiais" quanto em relação à forma como eles circulam e são reapropriados, deslocados, reconstruídos. Neste artigo, tratamos da produção de sentidos por uma narrativa dirigida por um estrangeiro (inglês) sobre o Brasil, com o objetivo de ser exibida em uma rede internacional de televisão (BBC), visando compreender a construção do Rio de Janeiro como "paraíso tropical distópico" no documentário Rio 50 Degrees Carry on Carioca.

\footnotetext{
${ }^{1}$ Para uma discussão acerca do conceito de cidade global no contexto dos megaeventos no Rio de Janeiro, veja-se o contributo de Gotardo, Freitas \& Brennand (2019).
} 
Dirigido por Julien Temple, cuja história profissional está intimamente ligada à produção de filmes documentais sobre músicos, bandas, festivais e clipes musicais, foi exibido e reapresentado pelo programa Imagine da rede britânica BBC entre maio de 2014 e setembro de 2016, antes da Copa do Mundo e após os Jogos Olímpicos. Com 1h45min de duração, o programa faz parte de uma extensa lista de documentários internacionais sobre a cidade produzidos e veiculados por redes de televisão durante o chamado "momento olímpico", composta tanto por produtos audiovisuais, os quais ratificam as narrativas oficiais, quanto aqueles que as deslocam, mostrando outras faces de uma marca-cidade almejada. O documentário aqui em análise faz parte do segundo grupo, tendo em vista que contesta as narrativas oficiais e diversos estereótipos, tal como será demonstrado no decorrer deste trabalho, que apresentará os primeiros 14 minutos do filme. A opção de restringir a análise aos minutos iniciais se justifica devido à função de "abertura" que esses 14 minutos possuem: eles apresentam uma ideia geral dos conceitos que são explorados de forma mais detalhada no restante do filme.

Considero, tal como Rose (2002: 343), que "os meios audiovisuais são um amálgama complexo de sentidos, imagens, técnicas, composição de cenas, sequência de cenas e muito mais"; e, tal como Aumont e Marie (2004: 39), que "não existe um método universal para analisar filmes" e que "a análise de um filme é interminável". Assim, busco realizar análises das narrativas de forma a desconstruí-las sob a luz da perspectiva teórica, buscando identificar os "modos como imagens, figuras e discursos da mídia funcionam dentro da cultura em geral" (Kellner, 2001: 77), sob a perspectiva do consumo desta cidade-mercadoria cuja marca foi reconstruída pelo city branding. Desta forma, ainda de acordo com Aumont e Marie (2004), procuro realizar a análise do filme como uma maneira de explicar de forma racionalizada os fenômenos observados nos filmes, com vista à produção do conhecimento e à interpretação.

\section{O paraíso tropical: da utopia à distopia}

A construção do Brasil como paraíso tropical é feita desde suas narrativas fundadoras, como Carta de Caminha, passando pelos mais diversos artefatos da cultura até os dias atuais. O belo, o exótico, a geografia maravilhosa, a paisagem do ócio, o deleite tropical, a generosidade da flora, da fauna e dos nativos permeiam imaginários tanto de brasileiros como de estrangeiros, tendo na cidade do Rio de Janeiro uma "representante" de toda a nação. Amâncio (2000: 22) salienta que "o Brasil pré-colonial evoca retrospectivamente uma mitologia da sedução do trópico, com sua paisagem paradisíaca e sua gente sensual e receptiva", onde "utopia, mito, miragem, febre de exotismo, é todo um repertório conceitual que vai se projetar na visão das Américas como uma infância da humanidade" (Amâncio, 2000: 29). 
Imagens de um bando de araras vermelhas ${ }^{2}$ voando iniciam o documentário inglês Rio 50 Degrees - Carry on Carioca, junto com a narração do apresentador, Alan Yentob, que se inicia em voz over:

Você sabe o que é um carioca? Todos no Rio são cariocas. É quente, quente, quente aqui. E está esquentando mais. Este é o momento do Rio, a Copa do Mundo, as Olimpíadas. É o 'boom' do Brasil. Será mesmo? Este filme de Julien Temple explora os altos emocionantes e os baixos aterrorizantes de um paraíso tropical distópico. ${ }^{3}$

Na sequência, ainda durante sua fala, o narrador aparece deitado sobre o calçadão de Copacabana, um plano feito por um drone, que segue subindo, abrindo a imagem e dando uma dimensão de grandeza a um dos símbolos da cidade; em seguida, novas imagens de uma arara sobrevoando um local onde a natureza parece estar intocada.

A primeira imagem do documentário, das araras, traz uma referência considerada icônica na construção dos imaginários sobre o país: o papagaio ${ }^{4}$. Segundo Amâncio (2000), houve um grande interesse dos europeus por essas aves desde o momento da chegada dos portugueses ao Brasil. Elas eram valorizadas nos mercados da Europa, segundo o autor, devido à associação com a fauna da Índia (Amâncio, 2000; Holanda, 2000). A ave era também muito associada a mitos religiosos: habitavam uma ilha milagrosa na viagem de São Brandão, descendiam dos anjos caídos após a revolta de Lúcifer, ou ainda, a outras transfigurações de anjos e às almas dos justos, e a ideia de terem sido os únicos animais a manterem a fala após o pecado original carregaria $o$ entendimento de que elas preservaram as virtudes dos primeiros tempos - o tempo dos Jardins do Éden. Além do papagaio, a imagem na natureza "intocada" também remete à construção da cartografia do "novo mundo" pelas narrativas fundadoras e em outros

\footnotetext{
${ }^{2}$ As araras vermelhas são aves que habitam a Amazônia brasileira e rios costeiros margeados por florestas no leste do País, tendo sido localmente extinta de lugares onde ocorria antigamente, como no Espírito Santo, boa parte da Bahia e possivelmente o norte do Rio de Janeiro (Arara-Vermelha-Grande, 2019). É considerada pelo ICMBio como espécie "quase ameaçada", ou seja, que pode vir a se enquadrar em uma categoria de ameaça em um futuro próximo (Instituto Chico Mendes de Conservação da Biodiversidade, 2018). Embora não seja possível comprovar, pois não há créditos das imagens, é possível / provável que tanto as imagens das aves quanto a imagem aérea da floresta tenham sido feitas no Pantanal ou na Amazônia, apesar do documentário ser sobre o Rio de Janeiro.

${ }^{3}$ No original: "Do you know what a Carioca is? Everyone in Rio is a Carioca. It's hot, hot, hot here. And it's getting hotter. This is Rio's moment, the World Cup, the Olympics. It's boom time in Brazil. Or is it? Julien Temple's film explores the exhilarating highs and the terrifying lows of a dystopian tropical paradise." As traduções aqui apresentadas são de minha responsabilidade.

${ }^{4}$ Apesar de serem espécies distintas, papagaios e araras são aves da mesma ordem (Psittaciformes) e mesma família (Psittacidae).
} 
textos que idealizam paisagens dos cenários edênicos, tal como salienta Holanda (2000: 258):

a amenidade do sítio corresponde bem à noção do homem feito à imagem de Deus; não se conhece ali neve ou granizo, e nada é triste ou corrupto; sem haver febre ocorre o antídoto, e não existindo defeitos na Natureza, já lá aparecem os remédios. Ausentes o horror hibernal e as intempéries, prevalece constante a primavera, e tudo quanto há vai em aumento pela própria harmonia do tempo. Para completar o quadro, no topo de cedro e de outras árvores, cantam a fênix, perenemente vivaz, e o papagaio, e uma só é a harmonia dos pássaros inumeráveis, louvando, cada qual à sua maneira, e celebrando, jubilosos, o Criador.

A imagem do Jardim do Éden carrega também um sentido de utopia. A vida imaginada como diferente, melhor que a conhecida, é característica constitutiva da humanidade, um desejo de transcendência como atributo universal, segundo Bauman (2003). Nesse sentido, podemos entender o "novo mundo" como paraíso utópico:

Novo não só porque, ignorado, até então, das gentes da Europa e ausente da geografia de Ptolomeu fora "novamente" encontrado, mas porque parecia o mundo renovar-se ali, e regenerar-se, vestido de verde imutável, banhado numa perene primavera, alheio à variedade e aos rigores das estações, como se estivesse verdadeiramente restituído à glória dos dias da Criação. (Holanda, 2000: 254)

O termo utopia, cunhado por Thomas More no ano de 1516, 24 anos após o descobrimento da América, refere-se a topos - um lugar, segundo Bauman (2003): as visões de vida diferentes eram sempre associadas a um território definido. Aqui, o termo se destaca do paraíso cristão para tomar corpo nas cidades. Na "modernidade sólida", o mundo é conscientemente territorial, tendo suas identidades ligadas ao território, unindo espaço e poder (o poder inscrito no reino da soberania e os Estados como autoridade e entidades territoriais). Utopia, nesse sentido, ainda de acordo com Bauman (2003), diz respeito a um reino de tranquilidade, certeza e estabilidade, constante e consistente. "As utopias eram os produtos finais antecipados da habilidosa implantação tanto da plasticidade do mundo quanto da nova (genuína ou suposta) liberdade de remodelar as condições humanas com o propósito de construir um mundo livre da maldição da incerteza" (Bauman, 2003: 16). Seu problema, segundo o autor, não diz respeito à potência da transcendência, mas sim, a sua articulação como projeto: "programas de mudança e de visões de vida coesos e abrangentes que a mudança espera provocar - visões que se destacam da realidade, esboçando uma visão completa e verdadeira, um mundo alternativo" (Bauman, 2003: 12).

Orellana (2010) descreve o conceito de utopia de More a partir da presença no termo do radical $-\mathrm{u}$ como um território a se descobrir, uma meta a se conquistar, um lugar 
possível de ser alcançado em algum ponto da Terra; um lugar diferente de todos os outros existentes, onde reina o ideal. Segundo Orellana, a perspectiva de More considera que os interesses mercantis e a propriedade privada rompem com a harmonia comunitária e, desta forma, uma sociedade utópica somente se construiria a partir de uma sociedade sem noção de propriedade ou que não utilize dinheiro, sendo o desejo a verdadeira fonte da desgraça humana. Ainda de acordo com Orellana, Aristóteles já mencionava a ideia de utopia urbana e Platão descreveu a república ideal, utilizando uma metáfora anatômica que equivaleria a um corpo são e asséptico, sem manchas nem contrastes, "que não pode ter lugar no real" (Orellana, 2010: 136). Outro conceito importante trazido pelo autor é o de Tommaso Campanella e sua Cidade do Sol, onde o poder fecha os espaços arquitetônicos e humanos, homogeneizando diferenças e interesses por meio da produção de corpos dóceis, convertendo-se numa espécie de totalitarismo.

Observa-se algumas questões trazidas até o momento para debate: a construção do Brasil como paraíso tropical utópico desde a chegada dos portugueses, um imaginário reproduzido ainda hoje das mais diversas formas e que no documentário em análise tem como representante a fauna e a flora; a construção da cidade ideal, global, da marca-cidade almejada pelas narrativas oficiais (governamentais), que utiliza os mega eventos como meio e fim para atingir seus objetivos; e o deslocamento desses conceitos pela narrativa do documentário a partir do entendimento do Rio de Janeiro "como paraíso tropical distópico", tal como descrito na abertura do programa pelo apresentador Alan Yentob.

Tunico Amâncio (2000), em seu estudo sobre a representação cinematográfica do Brasil em longas estrangeiros de ficção, revela que certos modelos instituídos pela indústria cinematográfica fazem parte de um repertório que se articula com textos fundadores (Carta de Caminha e relação de Gonneville) em quatro filiações principais: (1) Pero Vaz, que diz respeito à figura do viajante narrador que vive a relação de alteridade para confirmar uma imagem pré-concebida; (2) Essomericq, o emigrante, exilado, brasileiro como estrangeiro; (3) Afonso Ribeiro, o degradado, que precisa fugir da lei para ter uma nova oportunidade; e (4) Utopia, "a projeção de uma ilusão, de um desejo de alteridade, de exotismo, na busca de um espaço mitológico ou geográfico de realização" (Amâncio, 2000: 33). Acerca da filiação utopia, o autor destaca que, dentre os filmes que compõem o corpus de seu estudo, essa característica se dá especialmente em produções europeias: "intermediando o passado e o futuro, o Brasil vai ser ainda metáfora de mundos perdidos, ou ainda inalcançados (Amâncio, 2000: 114).

No que diz respeito às produções estadunidenses, elas possuem grande impacto na construção dos imaginários sobre o Brasil especialmente a partir da década de 1940, 
especialmente a partir da atuação do Birô Interamericano, que tinha por objetivo "promover a cooperação interamericana e a solidariedade hemisférica, mas que reforçava, na prática, a necessidade de proteção da posição internacional americana e a de enfrentar os desafios do Eixo" (Amâncio, 2000: 53). Nesse contexto, enquanto os Estados Unidos eram representados pelo poder bélico e industrial e pelos avanços técnicos e científicos, aos latino-americanos foram associados ao exótico, a uma relação de alteridade que se mantém por décadas: um mito que engloba "uma visão moderna, urbana e provinciana sustentada por manifestações folclóricas e exóticas cheias de colorido" (Amâncio, 2000:57). Repetição de lugares-comuns, banalização e preconceito marcam todo um leque de estereótipos e clichês que atravessam os filmes de ficção estrangeiros, construindo imagens do Brasil e do brasileiro a partir de articulações históricas, retóricas e simplificações sócio-culturais. E, dentro desses mais sólidos clichês, os planos aéreos do Rio de Janeiro, vistas paisagísticas por excelência, que demarcam campos de visibilidade e de significação.

Se produtos audiovisuais são um dos artefatos de construção das cidades utópicas (assim como da "cidade olímpica"), Arquitetura e Urbanismo são outro. Freitas (2011) ressalta as modificações urbanas e geográficas promovidas pelo então prefeito do Distrito Federal, Carlos Sampaio, para abrigar a Exposição Internacional de 1922, que buscava uma nova ordem baseada na importância financeira da mudança e na inserção da cidade do Rio de Janeiro como sede de grandes eventos e negócios. As mudanças de Carlos Sampaio seguiram as efetuadas anteriormente por Pereira Passos, baseadas em uma assepsia desejada internacionalmente, e justificadas como forma de acabar com as doenças e a miséria presentes no centro da cidade, sempre em nome de uma suposta melhoria na imagem do Rio de Janeiro, que contribuiria para uma melhor colocação da metrópole no cenário internacional ${ }^{5}$.

Assim, hoje, como no início do século XX, o Rio de Janeiro também passou por diversas mudanças arquitetônicas de larga escala para receber os mega eventos do século $\mathrm{XXI}^{6}$,

\footnotetext{
${ }^{5}$ Dentre as principais modificações urbanas promovidas nas gestões de Pereira Passos e Carlos Sampaio então a expropriação e demolição de cortiços, alargamento de ruas, modificação geográfica da cidade com o arrasamento do Morro do Castelo (visto como símbolo de um degradado passado colonial português; na área resultante, foi instalada a Exposição Internacional do I Centenário da Independência do Brasil) e aterramento da Praia de Santa Luzia e Enseada da Glória. As obras foram efetuadas principalmente no centro e na zona sul da cidade. Para mais informações acerca das mudanças urbanas na cidade do Rio de Janeiro, veja-se o contributo de Abreu 2011).

6 Dentre as modificações realizadas na cidade, destacam-se a construção dos corredores de transporte rápido de ônibus (BRT, sigla em inglês de Bus Rapid Transit), expansão do metrô para a Barra da Tijuca, reforma do estádio do Maracanã e o projeto de revitalização portuária do Rio, intitulado Porto Maravilha.
} 
baseadas em um ideal de se (re)colocar a cidade no cenário mundial de investimentos e turismo, seguindo as influências da globalização não apenas na esfera econômica, mas também na produção do espaço urbano, que passa a ser reconfigurado segundo orientações mercadológicas, gerando uma imagem ilusória de beneficiamento a todos os cidadãos, mas que resulta na comoditização do espaço urbano e em exclusões sócioespaciais as quais muitas vezes resultam em efeitos alienantes para os residentes das cidades (Sánchez \& Broudehoux, 2013).

O documentário aqui em análise resulta, então, da tensão entre a ideia do paraíso tropical, a cidade utópica, e os "efeitos" produzidos na construção da "cidade olímpica", uma cidade que exclui, apesar de (e talvez devido a) seu desejo asséptico e sua meta de tornar-se global. Nos termos de Sánchez e Broudehoux

o modelo de planejamento orientado por eventos promove uma visão exclusiva da regeneração urbana que pode abrir caminho para a privatização e mercantilização do espaço urbano assistidas pelo Estado, servindo assim às necessidades de capital, exacerbando a segregação sócio-espacial, a desigualdade e os conflitos sociais. (Sánchez \& Broudehoux, 2013: 133)

$\mathrm{Na}$ ideia da cidade distópica, muito explorada pela literatura e pelo cinema de ficção, a narrativa abandona os "mundos perfeitos" de More, Platão e Campanella para dar lugar à desesperança, à sociedade catastrófica, a uma perspectiva sombria comumente ligada a sociedades de um futuro apocalíptico, muito ligado ao desenvolvimento tecnológico (Orellana, 2010). Dentre os exemplos mais clássicos, pode-se citar, na literatura, Admirável Mundo Novo, de Aldous Huxley, publicado pela primeira vez em 1931; e 1984, de George Orwell, cuja primeira edição data de 1949; no cinema, destacam-se Blade Runner, de Ridley Scott (1982); Brazil, de Terry Gilliam (1985); e Matrix, das irmãs Wachowskis (1999); há diversos outros exemplos também na televisão, como a série The Handmaid's Tale, de Bruce Miller (2017 até o presente, totalizando três temporadas), baseada no livro homônimo de Margaret Atwood, publicado em 1985. No entanto, para o diretor do documentário, Julien Temple, trata-se de uma representação possível da sociedade carioca do passado e do presente.

Como pode ser visto nessas produções, a distopia retrataria uma sociedade de pesadelo em que se apresenta um jogo entre desesperança e felicidade. Para um observador externo, é evidente que a cidade descrita é um espaço trágico, embora seus habitantes insistam repetidas vezes em proclamar sua felicidade. Enquanto isso, na cidade utópica, o tema da felicidade era uma dedução lógica da

Para mais informações sobre as transformações da cidade do Rio de Janeiro para os megaeventos, ver Sánchez \& Broudehoux (2013). 
perfeição das condições de vida, na cidade distópica a afirmação da felicidade expressa a alienação de um sujeito que não reconhece a situação miserável em que se encontra. (Orellana, 2010: 141)

Após a fala do narrador, a música Rio 40 Graus, de Fernanda Abreu, é a trilha sonora de imagens que corroboram a ideia de "purgatório da beleza e do caos": um jogo de imagens contrastantes, atuais ou de arquivo, que mostram imagens de surfistas de trem $^{7}$ em vagões lotados, uma mulher que se exercita na praia, cachorros que passeiam no calçadão de Copacabana, a vista de um apartamento luxuoso de frente para o mar, a favela, as festas nas boates e dentro do trem, as danças, bebidas alcoólicas, a sensualidade, o estar-junto, a violência, o sexo e a sensualidade, entrecortadas por imagens de um termômetro que mostra a temperatura subindo - um resumo dos imaginários sobre o Rio de Janeiro entrecortados por imagens não tão comuns para estrangeiros. O documentário denuncia, especialmente durante os primeiros $14 \mathrm{~min}$, a diferença entre a imagem construída, a imagem almejada e a cidade vivida.

Outro exemplo da cidade distópica construída pelo documentário está na relação com o dinheiro, considerando especialmente que na construção da cidade utópica de Platão, More e Campanella a propriedade é uma das fontes de problemas e deve ser controlada ou combatida. Dois exemplos claros são apresentados logo no início do filme: no primeiro, a participação da socialite Narcisa Tamborindeguy como representante da riqueza e do consumo de luxo na cidade. Ela se hospeda no Copacabana Palace, onde nada na piscina. "Eu me sinto super bem no Copacabana Palace, como eu sou super bem recebida na Grande Rio, sabe, isso é o jeito de ser carioca, o contraste da cidade, do rico, do lixo com o luxo", diz. Cenas da socialite mergulhando na piscina são intercaladas com imagens de uma idosa lavando roupa em uma poça d'água que se forma em um buraco de uma via, onde duas pessoas também tomam banho. Após, imagens de Narcisa em uma festa luxuosa, uma banheira cheia de champanhe. A também socialite Val Marchiori, que participa da festa, diz, fazendo gestos com uma taça: "vou tacar champanhe no povo".

No segundo exemplo, o dinheiro também é usado como justificativa para a divisão da cidade entre Zona Norte e Zona Sul. Nelson Motta diz que o valor do metro quadrado de um imóvel em Ipanema é mais alto que em Park Avenue (Nova lorque). O documentário cita a divisão da cidade pelas montanhas e a necessidade de túneis para sua união, assim como menciona a diferença populacional nas duas áreas. Uma entrevistada diz que "o Rio parece [se resumir a] a Zona Sul", enquanto outra diz que

\footnotetext{
${ }^{7} \mathrm{O}$ "surfe ferroviário", como também é conhecido, é a prática de viajar sobre os vagões dos trens, desviando dos obstáculos. Foi uma prática muito popular nos anos de 1990 que causava muitos acidentes, inclusive com mortes (Netto, 1988, 1 de abril).
} 
"na Zona Sul as pessoas se acham melhores". Uma moradora de rua diz que na "na Zona Sul as pessoas são muito ignorantes" e que há muitos racistas, por isso ela prefere a Zona Norte. Um taxista diz que na Zona Norte os vizinhos são amigos e que a convivência é mais solidária, mas que é uma área muito perigosa, que não dá para fazer corridas para lugares não pacificados porque "o cara pode te pedir pra desovar um corpo", que você pode ser alvejado por um tiro por ser confundido. E encerra: "a diferença é a grana". O então prefeito do Rio, Eduardo Paes, também é entrevistado. Ele diz que é um carioca da classe média-alta, nascido na Zona Sul, e diz que "o grande desafio desta cidade tem sido, nos últimos anos, e será nos próximos anos, certamente, essa integração desse Rio de vários Rios".

Na separação da cidade devido ao abismo social gerado pela acumulação financeira (e na corroboração da ideia de "cidade partida"), constrói-se a distopia do paraíso tropical das matas e das aves. O paraíso edênico divide espaço com cenários de pobreza e de miséria, dando o tom do contraste entre paraíso utópico e cidade distópica. Mas a produção desses sentidos não se encerra nas imagens contrastantes, ela se dá também nos recursos de montagem, conforme veremos a seguir.

\section{Montagem como recurso para o contraste: imagens de arquivo e música}

Outra questão trazida logo no início do documentário é a construção dos imaginários sólidos sobre a cidade. Um instrutor de asa delta fala, enquanto voa: "aqui, onde os homens e as mulheres viram deuses. O Rio de Janeiro, devido a essa geografia onde as montanhas recortam o nosso litoral, ela trouxe para o carioca uma perspectiva aérea". Diversas imagens aéreas dos mais sólidos clichês da metrópole são exibidas ao som de Samba do Avião, de Tom Jobim, outro clichê da cidade. Amâncio (2000: 147148) reitera que

\footnotetext{
Essencialmente aéreas, as vistas introdutórias do Rio compõem o mais imediato leque de clichês sobre a cidade. Esta facilidade de composição plástica, possibilitada pela exuberante corografia, estabelece com a presença do mar - a Baía de Guanabara ou as praias oceânicas - um conjunto do qual a natureza tropical parece se nutrir para um efeito de espetacularidade. A natureza emoldura o nicho urbano e lhe dá substância pictórica.
}

A esse conjunto de imagens que compõe a apresentação da cidade em seus mais sólidos clichês acrescentam-se imagens de arquivo que corroboram os (e que contribuíram na construção dos) imaginários de estrangeiros sobre a cidade. Imagens do filme musical Flying Down to Rio (1933), com Fred Astaire, são exibidas: mulheres fazem uma coreografia na asa de um avião e o vento as deixa seminuas. Imagens do filme Interlúdio, de Alfred Hitchcock (1946), mostram Ingrid Bergman e Cary Grant 
chegando ao Rio de Janeiro e admirando a cidade de dentro do avião. Um documentário estrangeiro é exibido ${ }^{8}$, com imagens coloridas ou em preto e branco do carnaval, assim como imagens do filme Orfeu (1959). Raul Manso, taxista, diz que transporta muitos turistas, os quais sempre querem ir ao Cristo Redentor, Pão de Açúcar, Maracanã, quadras de escolas de samba, reiterando os imaginários sobre o consumo turístico da cidade, enquanto imagens de um mapa antigo são exibidas ao som de Mas que nada, de Sérgio Mendes, sobrepostas a imagens de arquivo de carnavais, de uma calopsita dançando e do próprio clipe da música em preto e branco, fechando um leque que compõe, em áudio e em visual, os imaginários mais sólidos da cidade.

A respeito dos arquivos, Foucault (2008) os entende como sistemas que instauram os enunciados como acontecimentos e coisas dentro das práticas discursivas. Não se trata da materialidade (documentos guardados) ou das instituições que os guardam, mas da possibilidade de aparecimento das coisas ditas graças ao jogo de relações que caracteriza o nível discursivo.

O arquivo é, de início, a lei do que pode ser dito, o sistema que rege o aparecimento dos enunciados como acontecimentos singulares. Mas 0 arquivo é, também, o que faz com que todas as coisas ditas [...] se agrupem em figuras distintas, se componham umas com as outras segundo relações múltiplas, se mantenham ou se esfumem segundo regularidades específicas; [...] é o que, na própria raiz do enunciadoacontecimento e no corpo em que se dá, define, desde o início, o sistema de sua enunciabilidade. [...] é o que define o modo de atualidade do enunciado-coisa; é o sistema de seu funcionamento. [...] é o que diferencia os discursos em sua existência múltipla e os especifica em sua duração própria. (Foucault, 2008: 147)

Na concepção foucaultiana, o discurso é objeto de desejo, é também aquilo pelo que se luta, é um poder do qual todos querem se apoderar (Foucault, 2000); e o arquivo, nesse contexto, atua como prática que permite a subsistência dos enunciados, mas também sua modificação; "É o sistema geral da formação e da transformação dos enunciados" (Foucault, 2008: 148, grifo do autor). No que diz respeito ao uso das imagens de arquivo no documentário, Mello (2014) ressalta, baseando-se em Didi-Huberman, que elas "são potentes e capazes de exigir um trabalho crucial da memória, produzindo uma incessante reconfiguração do passado" (Mello, 2014: 22). Nesse sentido, ao recolher as imagens de arquivo e construir novas associações e classificações a partir de seu uso,

\footnotetext{
${ }^{8}$ Como não há créditos nas imagens de arquivo, não foi possível identificar todos os filmes utilizados. No entanto, tratam-se de imagens de arquivos públicos, ou seja, produtos audiovisuais que foram produzidos para uma exibição pública a determinada audiência, entre filmes, imagens documentais, programas de televisão.
} 
os criadores questionam a posição das imagens como dispositivos conceituais, construindo novas posições.

O arquivo no cinema nada é antes de ser recolocado a serviço da montagem, pois existe uma tomada de posição de ordem política frente ao arquivo. Podemos pensar, então, que esta tomada de posição política dos arquivos está intimamente relacionada com as fraturas da história. Em outras palavras, podemos dizer que as lacunas dos arquivos serviriam como mecanismo de desvelo das chamadas fraturas da história, dentro de seus regimes de visibilidade e dizibilidade. (Mello, 2014: 22)

Três conceitos são essenciais na obra de Didi-Huberman para compreender a relação entre história e tempo na imagem: anacronismo, sintoma e sobrevivência. Por anacronismo entende-se o rastro (vestígio) característico das imagens, tal como uma marca ou sintoma que se expressa em outras imagens e tempos. O sintoma é aquilo que aflora as memórias, relações, semelhanças e tensões nas diversas temporalidades presentes nas imagens. A memória presente na imagem pode gerar tempos heterogêneos e descontínuos de acordo com a montagem - o anacronismo, o qual expressa a complexidade e sobredeterminação das imagens, consideradas um "campo de forças carregado de tempo complexo e impuro, ou seja, uma multiplicidade de tempos" (Mello, 2014). A importância da montagem, nesse sentido, está na constante atualização do presente e incessante reconfiguração do passado por meio de um movimento de construção da memória. $\mathrm{E}$, na montagem do documentário aqui em análise, a potência das imagens de arquivo busca, em consonância com imagens de entrevistas, memórias sobre a cidade, memórias essas que também atuam sobre os imaginários, além de mostrar processos de construção dos imaginários que perduram até os dias atuais. Julien Temple, ao resgatar essas imagens e reutilizá-las com outros recortes, em outros contextos, denuncia, de certa forma, as histórias contadas, os estereótipos sólidos construídos ao longo dos anos (também) por produtos audiovisuais, de ficção ou não, de forma a tensioná-los.

Nessa disputa conduzida pelo documentário, uma fala de Fausto Fawcett, cantor brasileiro identificado no documentário como street philosopher questiona as representações clássicas sobre o Rio de Janeiro: "esse cartão postal do chope ${ }^{9}$, da mulher, do futebol, da alegria, bla bla bla, é legal, mas é paralisante". Fawcett alerta, com suas palavras, sobre uma questão importante acerca dos estereótipos: embora não correspondam a uma suposta "verdade fundadora", são vistos enquanto tal e, portanto, são resistentes a mudanças; e eles também são úteis, pois, de acordo com Freire Filho,

\footnotetext{
${ }^{9}$ Chope é a cerveja servida a partir de barris de pressão, mais comumente servido em um copo de $300 \mathrm{ml}$ chamado tulipa. Em Portugal é conhecido por fino ou imperial.
} 
Herschmann e Paiva (2004: 3) "ambicionam impedir qualquer flexibilidade de pensamento na apreensão, avaliação ou comunicação de uma realidade ou alteridade, em prol da manutenção e da reprodução das relações de poder, desigualdade e exploração; da justificação e da racionalização de comportamentos hostis.".

Ainda no tensionamento por meio das imagens de arquivos, o documentário mostra cenas do filme Xica da Silva (1976). Enquanto a protagonista Zezé Mota encena uma dança com nudez, Fawcett reitera: "então fica aí quietinho porque você é o bom selvagem, alegre, erótico e servil". Essas críticas se referem à perfeição física, outro atributo explorado desde as narrativas fundadoras (Amâncio, 2000) que passa a ser explorado mercadologicamente (ligado especialmente a gênero e raça), segundo Gomes e Gastal (2015), com a criação da Embratur, durante a ditadura militar, devido à relevância que o turismo ganhava para o Brasil. Nesse período:

A Embratur divulgou intensamente a imagem do Brasil como país harmônico, reafirmando a identidade nacional em torno da mestiçagem / sexualidade / paraíso. Construiu, assim, a mulher brasileira como um atrativo turístico (Caetano, 2004; Gomes, 2009, 2010) ao utilizar, seguidamente, imagens de mulheres seminuas associadas a paisagens naturais, notadamente as praias, ou a eventos como o carnaval, nos materiais de divulgação turística. (Gomes \& Gastal, 2015: 212, grifo das autoras)

O ideal paradisíaco construído desde as narrativas fundadoras e reiterado tanto nos planos governamentais de turismo quanto nos mais diversos produtos midiáticos, como cinema (Amâncio, 2000) e televisão (Gotardo, 2016), é também parte dos imaginários de consumo turístico - ou, sob o ponto de vista institucional-mercadológico, são parte de uma estratégia para construir uma marca, criar atributos intangíveis para o país, de forma a criar diferenciação entre os competidores para atrair consumidores e, portanto, divisas (Freitas, Gotardo \& Sant'anna, 2015). A construção do corpo como atrativo turístico remonta ainda, segundo Gomes e Gastal (2015), ao imaginário da "Eva": a pecadora, a prostituta, a mulher hiperssexualizada, geralmente ligada à figura da "mulata"10, revelando uma dupla opressão - de gênero e de raça - tal como podemos ver por meio do uso das imagens do filme Xica da Silva.

Prosseguindo na análise do documentário, o então prefeito Eduardo Paes salienta, em entrevista registrada no Centro de Operações do Rio - um centro tecnológico de ponta

\footnotetext{
${ }^{10}$ Conforme destacam Gomes e Gastal (2015, p. 211), militantes do movimento feminista negro "criticam e buscam desconstruir o estereótipo da mulata, segundo o qual mulheres negras são entendidas como responsáveis pela sedução de homens brancos e, assim, pela fundação da nação mestiça ou da civilização luso-tropical. A denúncia do feminismo negro refere-se à ideologia da mestiçagem, vinculada à construção discursiva da hipersexualidade das mulheres negras, que oculta a opressão e a violência sexual que sofreram as mulheres negras escravizadas".
} 
onde o ex-prefeito gravou outras participações em documentários internacionais - que "a gente tem que deixar de ser uma espécie de paraíso tupiniquim, república das bananas. É o que a gente tem que mostrar, que essa cidade é uma cidade melhor, isso aqui, nós não queremos construir uma cidade para visitantes em busca de lugares exóticos dos trópicos, nós queremos uma cidade melhor para as pessoas que vivem aqui". Enquanto fala, imagens de arquivos mostram pessoas dançando em fantasias de bananas, pessoas trabalhando na colheita da fruta, uma pessoa ao lado de um índio, um artista de rua tocando guitarra na praia, os músicos da banda U2 na varanda do Copacabana Palace, o clipe da música Beautiful, de Snoop Dogg e Pharrell Williams e um mapa antigo sobre o corpo de uma mulher de biquíni, imagens que se contrapõem à fala do prefeito. Paes representa essa voz da marca "oficial", da construção que o planejamento estratégico almeja, desconsiderando os potenciais efeitos excludentes que a implantação do plano de reconstrução da cidade impunha a uma grande parte dos cidadãos, tal como apontaram Sánchez e Broudehoux (2013), e é questionado por imagens do filme.

Sobre essa cidade "melhor para as pessoas" (em detrimento de sua construção para consumo turístico, segundo o entendimento da fala de Paes) que o então prefeito tentava defender como projeto, uma entrevistada, deitada sobre o calçadão de Copacabana, salienta: "não é só o Rio de Janeiro maravilhoso, 'cidade maravilhosa', que gringo tá acostumado a ver". Ao som de País Tropical, de Jorge Ben Jor, um travelling que passa sobre a mata, sobre a favela, chegando até a praia. A entrevistada continua: "É uma cidade com conflitos, com favelas, com necessidades em educação, saúde, que não é tão mostrado lá fora e que deveria ser, porque vir pra cá e ver só os pontos turísticos é fácil, mas ver como é uma cidade de verdade, nem todo mundo consegue". A entrevistada denuncia a diferença da imagem da cidade que é construída versus a cidade que é vivida por seus cidadãos, contrariando a fala "oficial" de Paes.

Outra questão central na montagem para a condução da narrativa é a música que compõe a trilha sonora. Trata-se especialmente, neste caso, de uma característica do diretor Julien Temple, conhecido por ser um autor cuja história está ligada à produção de filmes documentais sobre músicos, bandas e festivais e também a clipes musicais. "A trilha sonora [...] participa da articulação e da organização da narrativa cinematográfica compondo um elemento de sua montagem. E desse modo, a percepção fílmica é 'áudio (verbo) visual' e permite numerosas combinações entre sons e imagens visuais" (Carvalho, 2007: 2).

É necessário, especialmente neste caso (mas também em todos os produtos audiovisuais), romper com a hegemonia da visualidade, buscando compreender o papel da música na construção de sentidos no documentário. Born (2013: 7) ressalta que a 
música é uma forma de mediação social, do som e do espaço, "seja na perspectiva de sua capacidade de engendrar modos de ser público e privado, sua constituição de formas de subjetividade e personalidade, sua ressonância afetiva ou sua incorporação na dinâmica capitalista de mercantilização e reificação", e ela também o é na produção audiovisual. Tal como Vila (2014), entendo que "as práticas musicais (e, em geral, quaisquer práticas culturais) são consideradas discursos com capacidades identitárias precisas" (Vila, 2014: 18) e, considerando, ainda como o autor, que os processos de identificação não estão ligados apenas de uma base discursiva, mas também a uma origem narrativa, é necessário apontar que esta é uma forma específica de discurso e que

permite a compreensão do mundo ao nosso redor de determinada forma que ações humanas são relacionadas umas com as outras e adquirem significado devido ao seu efeito na realização de objetivos e desejos. Em outras palavras, [...] a narrativa seria uma das mais importantes formas cognitivas que os seres humanos têm para entender a causalidade das ações dos agentes sociais. (Vila, 2014: 17)

Os produtos audiovisuais são discursos e, mais especificamente, são também narrativas. As músicas que compõem a trilha sonora desses audiovisuais também atuam no processo de construção de sentidos e, assim, também possuem função narrativa e discursiva, com uma particularidade importante: sua grande capacidade interpelatória, "porque ela[s] trabalha[m] com experiências emocionais intensas, experiências que são muito mais poderosas que aquelas produzidas por outros artefatos culturais" (Vila, 2014: 22).

As músicas utilizadas no documentário possuem relações estreitas com as imagens que as acompanham e apresentam uma característica diferenciada em relação a outros documentários pesquisados: são, em sua maioria, músicas brasileiras. Por exemplo, ao falar dos estereótipos, utiliza-se a bossa nova ou o samba-jazz, músicas de grande consumo internacional. Ao se falar dos contrastes da cidade, a música Rio 40 graus, com seu célebre verso "purgatório da beleza e do caos". O caminho do bem, de Tim Maia, é acompanhado por imagens das ruas com pessoas em situação de vulnerabilidade, dormindo nos bancos e calçadas, construindo um sentido de ironia para os lugares. Ao longo do documentário, a música indica os tempos e espaços, construindo e desconstruindo sentidos sobre eles. No entanto, fica a dúvida sobre a eficácia dessa estratégia, considerando que não há legendas no arquivo ao qual tive acesso e a língua poderia se apresentar como barreira para a compreensão, caso as músicas não tenham sido legendadas durante as exibições na televisão.

Músicas e imagens de arquivo são centrais para a montagem deste documentário, conduzindo a narrativa de uma forma a produzir sentidos que corroboram o ideia do 
contraste entre utopia e distopia, mas que também exercem uma importante função: tensionar os estereótipos e os clichês associados à cidade, mostrando que ela é muito mais diversa e que é uma cidade em conflito - não apenas o conflito armado, mas também em relação a uma violência simbólica que exclui em nome da reconfiguração da imagem da cidade para os megaeventos, para a criação de uma marca-cidade que se almejava cidade-global.

O oximoro utilizado para descrever o Rio - "paraíso tropical distópico" - é uma figura de linguagem que, pelo uso das palavras de sentidos opostos (dado que um paraíso seria uma utopia, jamais uma distopia), reforça a linguagem do filme de Temple: cheia de ironias e sarcasmo, também típicos do humor inglês. Trata-se de um documentário construído a partir de um jogo de imagens contrastantes, atuais ou de arquivo (que muitas vezes se confundem com imagens feitas exclusivamente para o documentário), e a produção desses sentidos não se encerra nessas imagens contrastantes, ela se dá também nos recursos de montagem, dos quais a música também é parte fundamental.

\section{Considerações Finais}

Antes de Rio 50 Degrees: Carry on Carioca, Temple havia dirigido London: The Modern Babylon, lançado em 2012, ano de realização dos Jogos Olímpicos na cidade, um filme com linguagem e objetivo semelhantes aos de Rio 50 Degrees. Em release divulgado pela Film London ${ }^{11}$ durante o Festival de Cannes de 2011, destaca-se a assinatura de contrato entre a Film London e a Rio Filmes que tinha por objetivo "desenvolver o intercâmbio de comércio, talento e cultura dentro das indústrias cinematográficas de suas cidades", tendo em vista que ambas cidades "são [ou eram, na ocasião] hubs de filmagem vibrantes, centros de comércio global e pontos de encontro para redes de negócios" (utilizando, nesses argumentos, temas centrais que se relacionam com o planejamento estratégico no city branding, como indústrias culturais e cidade global). Embora as aspas atribuídas a Temple destaquem seu fascínio pela cidade desde sua primeira visita na década de 1970 ("visualmente, o Rio é a mina de ouro de um cineasta e, através de sua música e das pessoas que o criam, tanto a alma da cidade quanto seu destino único encontram sua expressão máxima"), o release aponta o interesse de uso dos produtos audiovisuais no contexto do "momento olímpico" em que viviam as duas cidades. Lê-se na nota à imprensa:

\footnotetext{
${ }^{11}$ A Film London administra a British Film Commission através de uma parceria público-privada financiada pelo Departamento de Cultura, Mídia e Esporte.
} 
A parceria acontece quando Londres se prepara para passar para o Rio de Janeiro o papel de sediar os Jogos Olímpicos em 2016, após os Jogos de Londres em 2012. Embora o foco do acordo City to City seja compartilhar ideias e melhores práticas domésticas e produção internacional de filmes, também haverá colaboração sobre como as indústrias cinematográficas dessas duas cidades olímpicas podem explorar melhor a oportunidade única que oferece. Isso vai variar de como gerenciar a logística das filmagens durante os Jogos Olímpicos até o uso de filmes para capitalizar as oportunidades de turismo. ${ }^{12}$

Segundo matérias publicadas à época de pré-produção e produção ${ }^{13}$, Temple pretendia fazer um filme que se chamaria Children of the Revolution e abordaria as revoluções musicais na cidade a partir da década de 1960, incluindo o Rock in Rio Ele não objetivava fazer um estudo sociológico do Rio, como pontuou em uma de suas entrevistas, mas "mostrar esta cidade como um organismo vivo de cultura" (Fonseca, 2012, 6 de outubro). O projeto, no entanto, sofreu modificações, como se constata ao assistir ao filme, e é possível que o sucesso de London: The Modern Babylon tenha causado impacto sobre o resultado final de Rio 50 Degrees - carry on carioca. O documentário vai para além do que se propunha inicialmente tanto no tempo histórico quanto em seu tema principal, que deixa de ser a música, embora ela seja importante norteadora da narrativa e tenha função central na linguagem audiovisual. E o contexto de sua produção deixa clara a importância desse tipo de produto na construção da cidade olímpica.

A Copa do Mundo e os Jogos Olímpicos foram meio e fim para um processo de reconfiguração da imagem da cidade. Para tanto, foram utilizadas técnicas de city branding - modelo desenvolvido no campo do Marketing, a partir de uma visão da Administração e da cidade enquanto produto, e não como lócus de circulação dos imaginários contemporâneos. Esse modelo é "vendido" mundo afora há cerca de 30 anos como "solução" para diversos problemas, em uma visão que "molda" novos modos de ser, estar e viver na cidade, gerando uma nova ideia de cidadania (Sánchez, 2010) - e os meios de comunicação são elementos-chave na construção dessas novas subjetividades.

\footnotetext{
12 No original: "The partnership comes as London prepares to pass on to Rio de Janeiro the role of hosting the Olympic Games in 2016, following the London Games in 2012. While the focus of the City to City agreement will be to share ideas and best practice on domestic and international film production, there will also be collaboration on how the film industries of these two Olympic host cities can best exploit the unique opportunity it offers. This will range from how to manage the logistics of filming during an Olympic Games to using film to capitalise on tourism opportunities." (London and Rio sign city to city agreement, 2011).

${ }^{13}$ Veja-se: Albuquerque (2011, 14 de agosto) e Fonseca (2012, 6 de outubro).
} 
$\mathrm{Na}$ disputa discursiva sobre a produção de sentidos acerca da cidade olímpica, Julien Temple promove em seu filme importantes deslocamentos em relação aos sentidos produzidos pelos discursos oficiais utilizando recursos de montagem, a partir por exemplo do uso de imagens contrastantes e de arquivo, as quais promovem tensionamentos em relação aos mais sólidos estereótipos e clichês da cidade com um potencial de reconfiguração do passado, com possíveis novas associações e classificações; a partir da música, muitas vezes utilizada de forma irônica e em contraste com as imagens, ou mesmo como contextualização histórica da produção de clichês; e a partir dos textos / falas, como por exemplo quando o apresentador questiona se esse é mesmo o "momento do Rio". A importância deste filme se dá ainda pelo fato de que esses discursos desviantes entraram em circulação na mídia hegemônica, colocando em xeque, de certa forma, todo aparato de construção da cidade olímpica pelos efeitos produzidos pela estratégia de megaeventos no Rio de Janeiro.

Apenas nos primeiros 14 minutos, Rio 50 Degrees - Carry on Carioca promove um grande e importante tensionamento nos imaginários relacionados à cidade, que é apresentada como "paraíso tropical distópico". Áudio e visual compõem um leque de representações que denunciam um reducionismo da cidade aos seus estereótipos, a distância entre o discurso oficial da marca e cidade vivida, a colonização dos corpos, o abismo social entre os mais ricos e os mais pobres: uma cidade moldada pela geografia maravilhosa do paraíso edênico, mas que carrega o estigma das narrativas distópicas futuristas em seu passado e presente. Mas também, uma cidade plural, que vive todos os seus espaços das mais diversas formas, apesar de estes serem excluídos na conformação da marca-cidade.

O presente trabalho foi realizado com o apoio da Coordenação de Aperfeiçoamento de Pessoal de Nível Superior - Brasil (Capes) - Código de Financiamento 001.

\section{Referências bibliográficas}

Abreu, M. de (1987). A evolução urbana do Rio de Janeiro. Rio de Janeiro: IPLANRIO e Zahar.

Albuquerque, C. (2011, 14 de agosto). O inglês Julien Temple volta ao Rio para filmar documentário. O Globo. Consultado em: https://oglobo.globo.com/cultura/o-inglesjulien-temple-volta-ao-rio-para-filmar-documentario-2690948.

Amancio, T. (2000). O Brasil dos gringos: imagens no cinema. Niterói: Intertexto.

Arara-vermelha-grande (2019). Wikiaves. Consultado em: https://www.wikiaves.com.br/wiki/arara-vermelha. 
Aumont, J. \& Marie, M. (2004). A análise do filme. Lisboa: Edições Texto e Grafia.

Bauman, Z. (2003). Utopia with no Topos. History of the Human Sciences, vol. 16, n.1: $11-25$.

Born, G. (2013). Introdution - music, sound and space: transformations of public and private experience, in G. Born (ed). Music, Sound and Space. Transformations on Public and Private Experience. Cambridge: Cambridge University Press.

Carvalho, M. (2007). A trilha sonora do Cinema: proposta para um "ouvir" analítico. Caligrama (São Paulo. Online), 3(1): doi: 10.11606/issn.1808-0820.cali.2007.65388

Comitê de candidatura do Rio 2016 (2009). Dossiê de candidatura do Rio de Janeiro a sede dos Jogos Olímpicos e Paraolímpicos de 2016 vol.1. Consultado em: http://memoriadasolimpiadas.rb.gov.br/jspui/handle/123456789/594

Foucault, M. (2000). A ordem do discurso. São Paulo: Loyola.

Foucault, M. (2008). A arqueologia do saber. Rio de Janeiro: Forense Universitária.

Filho, J. F., Herschmann, M. \& Paiva, R. (2004). Rio de Janeiro: estereótipos e representações midiáticas. E-Compós, v. 1: 1-25. doi: 10.30962/ec.1.

Fonseca, R. (2012, 6 de outubro). Julien Temple, o cineasta que garimpa sons da cidade. O Globo. Consultado em: https://oglobo.globo.com/cultura/julien-templecineasta-que-garimpa-sons-da-cidade-6300792.

Freitas, R. F. (2011). Rio de Janeiro, lugar de eventos: das exposições do início do século XX aos megaeventos contemporâneos. In: Compós, Anais Cómpos 2011 - XX Compós: Porto Alegre/RS (pp.1-12). Porto Alegre: UFRGS. Consultado em: http://www.compos.org.br/data/biblioteca_1639.pdf.

Freitas, R. F.; Gotardo, A.T. \& Sant'Anna, C.N. (2015). Ativos intangíveis na marca rio: o consumo turístico da cidade nos documentários internacionais. In: Compós, Anais Compós 2015 - XXIV Compós: Brasília/DF (pp.1-17). Brasília: UnB. Consultado em: http://www.compos.org.br/biblioteca/compos-2015-3920767f-7bd6-40ea-a794-

9588923ea16d_2804.pdf.

Gomes, M.S. \& Gastal, S. (2015). Evas e Marias no turismo do Brasil: o corpo como atrativo turístico e signo de hospitalidade, in D.C.O. Siqueira (Org.). A construção social das emoções: corpo e produção de sentidos na Comunicação (pp. 207-226). Porto Alegre: Sulina.

Gotardo, A.T. (2016). Rio para gringo: a construção de sentidos sobre o carioca e a cidade para consumo turístico. Dissertação de Mestrado, Universidade do Estado do Rio de Janeiro, Rio de Janeiro, Brasil. Consultado em: http://www.ppgcom.uerj.br/wpcontent/uploads/Disserta\%C3\%A7\%C3\%A3o-Ana-Gotardo.pdf.

Gotardo, A.T.; Freitas, R.F. \& Brennand, J.M.A. WELCOME TO RIO: imaginários e interfaces entre cidade global e economia criativa. In Compós, Anais Compós 2019 XXVIII Compós: PUC/Porto Alegre (pp. 1-21). Porto Alegre: PUCRS. Consultado em: http://www.compos.org.br/biblioteca/trabalhos_arquivo_689TP5JHPZX9RXJ14WIQ_28 _7710_21_02_2019_13_03_51.pdf. 
Holanda, S.B. (2000). Visão do Paraíso: os motivos edênicos no descobrimento e colonização do Brasil. São Paulo: Brasiliense.

Embratur Instituto Brasileiro do Turismo (2009). Plano Aquarela 2020: marketing turístico internacional do Brasil. Consultado em: http://www.embratur.gov.br/lai_embratur_secom/export/sites/lai/galerias/download/Plan o_Aquarela_2020.pdf

Instituto Chico Mendes de Conservação da Biodiversidade (2018). Livro Vermelho da Fauna Brasileira Ameaçada de Extinção vol. i. Consultado em: http://www.icmbio.gov.br/portal/images/stories/comunicacao/publicacoes/publicacoesdiversas/livro_vermelho_2018_vol1.pdf

Kellner, D. (2001). A cultura da mídia. Bauru: EDUSC.

London and Rio Sign City to City Agreement (2011, 17 de maio). Film London. Consultado

em:http://filmlondon.org.uk/about/press_releases/2011/may/london_and_rio_sign_city_ to_city_agreement

Mello, J.G. (2014). O arquivo como sintoma: anacronismo das imagens na obra de Harun Farocki. Revista Passagens, vol. 5, n. 1, 20-34.

Netto, F. C. (1988, 1 de abril). Dois repórteres da Trip registram a ousadia e o protesto dos surfistas ferroviários no Rio. Revistatrip. Consultado em: https://revistatrip.uol.com.br/trip/mar-raivoso-a-ousadia-e-o-protesto-dos-surfistasferroviarios-no-rio-de-janeiro .

Orellana, R.C. (2010). Ciudades Ideales, Ciudades sin Futuro. El Porvenir de la Utopía. Daímon - Revista Internacional de Filosofía, Suplemento 3: 135-144.

Rose, D. (2002). Análise de imagens em movimento, in M. W. Bauer \& G. Gaskell (eds). Pesquisa qualitativa com texto, imagem e som (pp.343-364). Petrópolis, Rio de Janeiro: Vozes.

Sánchez, F. (2010). A reinvenção das cidades para um mercado mundial. Chapecó: Argos.

Sánchez, F. \& Broudehoux, A. M. (2013). Mega-events and urban regeneration in Rio de Janeiro: planning in a state of emergency. International Journal of Urban Sustainable Development, vol.5, n.2: 132-153.

Temple, J. (2014). Rio 50 Degrees. [Documentário]. Reino Unido, Brasil e Alemanha: Killerpic Limited, Film and Music Entertainment (F\&ME), 2 Pilots Filmproduction, TV Zero e BBC Television.

Vila, P. (2014). Narrative Identities and Popular Music: Linguistic Discourses and Social Practices, in P. Vila (ed.). Music and youth culture in Latin America: identity construction processes from New York to Buenos Aires (pp.17-80). Nova lorque: Oxford University Press. 
Ana Teresa Gotardo é doutoranda pelo Programa de Pós-Graduação em Comunicação da Universidade do Estado do Rio de Janeiro (PPGCOM / UERJ / Brasil), com estágio doutoral (bolsa Capes, código de financiamento 001) no Department of Urban Studies and Planning da University of Sheffield. Mestre em Comunicação (UERJ, 2016). Especialista em Marketing Estratégico (PUCRS, 2008). Graduada em Comunicação Social com ênfase em Relações Públicas (UFRGS, 2004). Atua profissionalmente como técnico-administrativo - Relações Públicas na Universidade Federal Fluminense (UFF / Brasil).

凶aninhate@gmail.com 